\title{
Cross-Border M\&A and Financial Performance: Empirical Evidence on Bidder/Target Companies
}

\author{
Valentina Cioli $^{1}$, Alessandro Giannozzi ${ }^{1}$, Valentina Ippoliti ${ }^{2} \&$ Oliviero Roggi $^{3}$ \\ ${ }^{1}$ School of Management-Business and administration department, University of Florence, Italy \\ ${ }^{2}$ University of Florence, Italy \\ ${ }^{3}$ University of Florence, Italy; Fundação Dom Cabral, Brazil \\ Correspondence: Alessandro Giannozzi, School of Management-Business and administration department - \\ University of Florence, Italy. E-mail: alessandro.giannozzi@unifi.it
}

Received: January 30, 2020

Accepted: February 20, 2020

Online Published: March 9, 2020

doi:10.5539/ijbm.v15n4p67

URL: https://doi.org/10.5539/ijbm.v15n4p67

\begin{abstract}
Achieving successful integration of mergers and acquisitions (M\&A) continues to pose serious challenges for cross-border acquirers. The aim of this paper was to analyze the impact of cross border M\&A on bidder and target companies' post-M\&A profitability, leverage and growth in sales/invested capital. We used a sample of 415 Italian bidder companies and 370 Italian target companies over the period of 2006-2013. Our analysis suggests that the cultural distance exerts positive effects on bidder companies' post-M\&A performance and a negative effect on target companies. Bidder companies better exploit the source of value in terms of competencies and resources, learning from their counterparties. The results suggest that the effect of culture distance is conditioned by the acquirer size, prior experience and managerial capabilities in dealing with cross-border cultural challenges. Profitability ratios show a significant increase in bidder companies, while target companies do not reveal any significant change in the comparison pre-post M\&A. Leverage reveals no significant difference in bidder companies, while target companies have a higher leverage after a cross-border M\&A. In cross-border M\&A, the private equity funds as acquirer do not generate any incremental benefit from the target companies' post M\&A performance.
\end{abstract}

Keywords: mergers \& acquisitions, cross-border; financial performance, cultural distance, international management

\section{Introduction}

The M\&A market is expanding globally to new countries and new sectors. The economic context is modifying the intensity and direction of cross-border M\&As, updating continuously determinants and critical success factors of these operations. Achieving successful integration of mergers and acquisitions continues to pose serious challenges for cross-border bidders and targets. A cross-border merger and acquisition occurs when an operating enterprise acquires control over the whole or a part of the business of another enterprise outside its country. Opportunities offered from this type of operation are related to synergies to create value in terms of the optimization of costs and maximization of profits, keeping companies competitive in a growing global market (Neary, 2007). The main concern is connected to the capacity to succeed in benefiting from these advantages. Because many issues must be considered to evaluate post cross-border M\&A performance, the result can differ extensively. The shades taken after an M\&A operation are not equal, and thus, theme is still debated presently, and different internal and external factors are studied to have a wide overview. In fact, the statement regarding the increase in growth through acquisition depends on the economic environment and other driving forces that need to be carefully considered. Italian M\&A activity has achieved positive results because of a series of phenomena: consolidation of some industrial sectors, business reposition, internationalization, and Italian and foreign private equity interests (Kpmg, 2018). Nevertheless, a series of factors is considered to measure the final impact on different industrial sectors. Kpmg research (2018) has shown that geopolitical uncertainties, such as the first year of the Trump presidency in the United States, the beginning of Brexit and, in the first half of the year, the outcome of the French elections, only partly affected global mergers and acquisitions. Indeed, 2017 was a record year for the number of completed transactions $(37,437$ deals, up $7 \%$ on the previous year), while values slipped slightly (-9\%) to nearly $\$ 3,000$ billion (completed M\&As, target). Analysis of the second quarter of 2017 
showed a strong cross-border market around a range of challenges (Mergermarket, 2017). Uncertainty surrounding Brexit, European elections and President Trump's future policies are weighted heavily on dealmakers' decisions. Cross-border mergers and acquisitions (M\&As) have become globally increasingly important, accounting for $47 \%$ of the global value of M\&As in 2017, versus $49 \%$ in 2016 and $45 \%$ in 2015 in terms of deal value (completed M\&As, target or acquirer). Country risk factors are important in explaining bidders' performance in cross-border M\&A. In the U.S. Kiymaz (2013) found direct relationships between performance and economic risk rating and inverse relations between gains and financial and political risk ratings. Also, economic development of target, correlation in GNP growth, economic outlook in the host market, and exchange rate volatility relate significantly to bidders gains. In fact, managers are more competent in cross-border acquisitions; thus, firms can deliver on their deal objectives, but this phenomenon is historically recent. Therefore, executives remain cautious in a climate of global economic and political instability. 2016 was a vibrant year for M\&As, where deal volumes and deal counts supported substantial global uncertainty (geopolitical changes, heightened regulatory scrutiny and speculation around both Brexit and China). Notwithstanding all of these pressures, the market remained dynamic. Despite this volatile backdrop, cross-border activity in 2017 accounted for $47 \%$ of global value and $36 \%$ of volume. Specifically, Europe was the hot target country recording most of the cross-border deal making by value $(41 \%$ by volume and $58 \%$ by value, with 321 deals totaling $\$ 138$ bn). The main bidder into EU was North America, while the main European target was Germany. China was the second highest bidder cross-border country in Q2 2017 with 94 deals valued at $\$ 35.9 \mathrm{bn}$. The Middle East has emerged as a powerful force within the global cross-border deal market with two large outbound deals.

Referring to Italy in 2016, cross-border activities became a structural part of the Italian M\&A market, setting a new record of 426 completed deals ( $+43 \%$ on 2015); in 2017, they remained steady, with volumes of 425 completed deals, in line with the record set in 2016, while values of $€ 31.6$ bn almost matched the previous year $(-2 \%)$. In relative terms, cross-border M\&As accounted for approximately $70 \%$ of the total Italian market, versus $56 \%$ in 2016. However, these deals show a decreasing trend of value from 2015: $€ 31.6$ bn in 2017 vs $€ 32.1$ bn in 2016 vs $€ 42.3$ bn in 2015. The problem is the decrease in Italian acquisitions abroad (19\% in 2017) and the lower value of incoming cross-border deals (49\%) vs that in 2015 (57\%). Particularly, foreign investments involving Italy grew, accounting for 266 deals, and 19\% of the Italian acquisitions abroad decreased slightly with 159 completed deals. Consequently, the net number of cross-border deals-out transactions involving foreign investors in Italy rose to 107 transactions, compared with a net balance of 96 foreign acquisitions in Italy in 2016

The aim of this paper was to build knowledge to analyze whether cross-border M\&As created value in bidder and target companies, which are the potential determinants of cross-border deals completed and received by Italian companies in non-financial sectors from 2006 to 2013 in Asia, North America and the rest of Europe. We used a post-performance M\&A scenario and two samples: the first is based on bidder companies and the other on target companies. Value creation was measured by accounting and financial measures extracted from the MergerMarket database, Amadeus database and Bloomberg. Potential determinants of cross-border M\&As on the bidder and target post-performance include cultural, economic and deal factors.

The paper is divided into four sections: the first section is a literature review on M\&A integration and cultural problems associated with combining organizations in cross-national settings; the second section explains the data and research methodology; the third section analyzes the results and presents some robustness tests of our models; the final section concludes with suggestions for future research.

\section{Literature Review and Hypothesis}

Many studies have been published on the effects of mergers and acquisitions on share prices, shareholder wealth, and the pre- and post-merger operating and financial performance of target and bidder firms. There is no conclusive evidence on whether M\&As enhance efficiency. The literature review is classified into three research areas: "Studies using Accounting Measures" (Antikainen, 2008) (Bertrand \& Betschinger, 2012), "Stock market studies" using "Event Study approach" (note 1) (Megginson, Morgan, \& Nail, 2004), (Alexandridis, Mavrovitis, \& Travlos, 2012), (Aybar \& Ficici, 2009) (Anand, Capron, \& Mitchell, 2005) and studies using "Multiple Performance Measures" with the balanced scorecard analysis (note 2). Event study approach reflect non only business performance linked to corporate control but also investors sentiment therefore stock prices could incorporate behavioural bias and valuation errors. Moreover the efficiency of event study is discussed because it is a short term analysis.

Studies based on accounting data focus on changes in profitability (EBIT or net income) or other financial 
measures (pre-tax cash flow o turnover) comparing pre-M\&A measures with post-M\&A ones by parametric tests in a long period. To adjust for size, these measures are divided by assets, sales, and equity. An adjustment was also made for the industry trend.

In both approaches, there has been considerable debate regarding the most appropriate and accurate way to assess M\&A gains, both in terms of indices used and the appropriate time span over which to judge performance. In fact the success of an acquisition depends on the ability to create added value after it has occurred, however, the mere existence of potential value creation or synergism is no guarantee that this possibility will be realized.

If we look at the overview of the empirical studies on post-acquisition operating performance, we understand that the world's researchers have different and opposite positions, also referring to the same country. Some US studies have shown that the profitability of the bidding and target firms remains unchanged (Moeller, Schlingemann, \& Stulz, 2004); (Ghosh, 2001) or significantly improves after the takeover (Heron and Lie, 2002); (Linn \& Switzer, 2001). Studies on UK firms found a significant decline in the post-acquisition performance (Dickerson et al. 1997) or a significant growth (Powell and Stark, 2005). Asian studies have shown that Japanese M\&As incur a decrease in the post-acquisition operating performance of the merged firm (Kruse et al., 2002); (Yeh \& Hoshino, 2002), while Malaysian takeovers are associated with better post-acquisition performance (Abdul Rahman \& Limmack, 2004) and recently Rao-Nicholson, Salaber, \& Cao (2016) in ASEAN countries found that during the crisis certain characteristics of the firms (size of the target, cross-border M\&A, friendly nature of deals) are important determinants of long-term post-M\&A operating performance. Australian M\&As led to insignificant changes in the profitability of bidding and target firms after the takeover (Sharma and Ho, 2002). Some continental Europeans studies referring to the World found a significant decline in post-acquisition sales of the combined firm but an insignificant increase in post-acquisition profit (Gugler, Mueller, Yurtoglu, \& Zulehner, 2003).

In our work, we focused on cross-border M\&As, and in this field, some studies have indicated that M\&As can have a negative impact on the economic performance of the new entity (Tetenbaum, 1999); (Cartwright \& Cooper, 2011). However others (Nadolska \& Barkema, 2007) see a growth in financial performance post cross border acquisition, at least in the short run.

Many studies have distinguished between the 'hard' (performance-related) and 'soft' (cultural) issues in investigating the success or failure of cross-border M\&As. More recently, the management of 'soft' factors in the post-acquisition process has been highlighted as a crucial factor. Therefore latter approach is pursued in the present research, with an emphasis on cultural factors, while the performance outcomes focus on a mixture of hard and softer measures. What is clear from this literature review overall is that identifying a successful management formula for the post-acquisition process is a crucial yet daunting task.

After reviewing literature carefully we acknowledge that many tools and techniques are available to analyze the effects of merger and acquisition deals. We refer only to accounting measures and financial ratios, but found different measures in various studies in this research area (Kumar \& Bansal, 2008). Therefore, we divided the existing studies to identify the best variables for our models.

First, we can refer to Gugler et al., 2003 and Abdul Rahman \& Limmack, 2004 who analyzed the improvement in the post-acquisition operating performance in the world and US using sales and EBIT as performance measures. They tested the hypothesis related to an improvement in the operating measures with a lower growth rate in sales with respect to overall profits for target companies. Others (Camerlynck, Ooghe, \& De Langhe, 2005 ) found that acquiring companies achieved a higher growth rate in assets and sales than target companies but both are highly levered, therefore there were difference in growth, but similarity in capital structure between acquirers and their targets. A lower profitability for target companies with respect to acquiring firms has been studied by other authors. Moreover, Herman \& Lowenstein (1988) reported a decrease in the post-acquisition operating performance regarding the return on capital (ROC) in a study conducted for all transactions involving all industrial sectors. This study examined the variation in the return on assets (ROA) and return on invested capital (ROIC) to consider the cash adjustment. Specifically, the variables involved are growth in sales, net income and invested capital, while profitability is measured by EBITDA, EBIT, profit margins and ROA (Ashfaq, Usman, Hanif, \& Yousaf, 2014) or ROIC. There is also empirical evidence that M\&A deals do not significantly influence the profitability and financial performance of corporate firms (Pilloff, 2006). However, other studies (Rashid \& Naeem, 2017) have suggested that the merger deals in Pakistan do not have any significant impact on the profitability, liquidity, and leverage position of the firms but only on the target quick ratio. Others ( $\mathrm{P}$ Mantravadi \& Reddy, 2008) (Pramod Mantravadi \& Reddy, 2008) found minor variations in terms of impact on the operating performance following mergers in different industries in India. Particularly, mergers have a 
positive impact on the profitability of firms but only in the banking and finance industries. Pharmaceuticals, textiles and electrical equipment sectors saw a marginal reduction in the performance in terms of profitability and returns on investment. For the chemicals and agri-product sectors, performance after mergers declined, both in terms of profitability margins and returns on investment and assets.

Thus, we believe in a significant growth and profitability for bidders but not for targets, and the following hypotheses were generated.

Hypothesis 1: Cross-border M\&As have significantly improved the growth of bidder firms in terms of sales, profit and invested capital, but they do not affect the target's growth.

Hypothesis 2: Cross-border M\&As have significantly improved profitability of bidder firms, but they do not affect the target company's profitability

To examine how M\&As influence the efficiency of companies in using assets, we chose the net asset turnover. Even if growth in sales is expected for bidder companies, no significant changes are expected in this ratio because the increase in the size of the assets and invested capital compensates for the increase in sales overall in the short-term period after an M\&A transaction. This statement can be used for both bidder companies and target companies, revealing the next hypothesis.

\section{Hypothesis 3: Cross-border M\&As have not improved the capital turnover of bidder and target firms}

There is no wide literature on the effect of a cross-border M\&A on the capital structure of the bidder or target company, particularly on leverage. Considering the sample analyzed in this research, we refer to Linn \& Switzer, 2001, Clark \& Ofek, 2006 and Rashid \& Naeem, 2017 who found no significant relationship between the acquirer's leverage and post-merger operating performance. In a study conducted in the manufacturing sector by Mishra, Leepsa, Sekhar, Corresponding, \& Gupta, 2012, improvement in leverage is not statistically significant.

Thus, this hypothesis was reported.

\section{Hypothesis 4: Cross-border M\&As do not affect the financial leverage of bidder and target firms}

Public acquirers are more confident in acquiring public targets because they expect a higher value-added post-performance M\&A. Moreover, the lack of information on private firms limits the breadth of the acquirer's search and increases the risk of an improper evaluation (Ragozzino \& Reuer, 2007). On the other hand, acquirers of private targets can better appropriate the percentage of the value from acquisitions because targets have a weaker bargaining power than public ones. Therefore, the literature about it is not homogeneous. However, considering that the samples selected involved cross-border and not domestic M\&As, the risk related to the company acquired was higher in the case of private companies than in the case of public companies (Capron \& Shen, 2007). Therefore, we believe in a higher post-operating performance in the case of transactions among public companies using the following hypothesis:

Hypothesis 5: Cross-border M\&As among public companies improve post performance for bidder and target firms

If we look at deal value, there is much literature that asserts the higher the deal value is the higher the impact on post M\&A performance will be for both acquiring and target companies. Thus, the following hypothesis was generated.

Hypothesis 6: The size of the deal value exerts a positive effect on post M\&A performance for bidder and target firms

If we consider cultural factors, there is significant evidence in the literature concerning the negative impact of cultural variables on post M\&A performance with some exceptions related to the integration process (Chakrabarti, Gupta-Mukherjee, \& Jayaraman, 2009); (Sarala, Junni, Cooper, \& Tarba, 2016). According to Stahl \& Voigt (2008), a company's ability to create value by exploiting intangible assets in distant cultures is determined by its capacity to overcome and use this distance because cultural distance affects the synergy and learning stimulus, potential knowledge transfer, and transaction costs related to geographic diversification and intracultural contact (note 3). Incompatibility and implementation problems during the integration process in acquisitions involving very distant cultures can eventually harm learning and synergies (Hagendorff \& Voss, 2010). However, there are some exceptions. Some Authors (G. Stahl, Björkman, Goulet, \& Schweiger, 2013) argue that M\&A partners are more predisposed to manage cultural differences because they focus on national cultural factors. Similarly, Evans, Pucik, and Barsoux (2002) note that managers of cross-border M\&As are more sensitive to cultural issues than those of domestic mergers. Some other studies argue that cultural distance improves cross-border acquisition performance by providing access to the target's and acquirer's diverse set of 
routines embedded in national culture (Hofstede, 1980); (Kogut \& Singh, 2003); (Morosini \& Singh, 1994). Drogendijk \& Slangen (2006) demonstrated that cultural distance in and of itself does not have an effect; it all depends on how closely the acquirer seeks to integrate the acquired company. The author states that, at low integration levels, cultural distance is a boon; at high integration levels, it is a bane. Following this thinking, other authors (Dikova \& Rao Sahib, 2013) suggest that the effect of cultural distance on cross-border acquisition performance depends on the level of acquisition experience of the acquirer. More internationally experienced acquirers can know cross-border acquisition pitfalls and they are more skilled at resolving acquisition-related conflicts. This allows the acquirer to benefit from cultural differences, ultimately leading to higher acquisition performance, but it does not occur every time. A thorough evaluation of cultural fit can improve the cross-border acquisition performance. It can increase the awareness of the target firm's culture and assist in determining the degree of change required or degree of accommodation needed to achieve post-acquisition success. An acquiring firm that does not carry out a thorough evaluation of cultural fit runs the risk of implementing inappropriate changes that are likely to lead to post-acquisition difficulties and even failure (Ahammad \& Glaister, 2013).

Therefore, the impact on performance could differ depending on the experience of acquirers and we prefer to test the following hypothesis:

\section{Hypothesis 7: Cultural distance does not affect post $M \& A$ performance for bidder and target companies}

We expect that economic differences between target and bidder nations may have a considerable effect on performance. Differences in per capita GDP are often associated with major socio-economic differences between countries. Therefore, we used the per capita GDP difference (Chakrabarti et al., 2009) as a proxy variable for economic growth distance. Moreover, referring to the same authors, we considered the foreign exchange rate volatility in a target country as a factor that can play a role in determining the success of a cross-border acquisition (Collins, Holcomb, Certo, Hitt, \& Lester, 2009). We expect to find positive synergies between bidder firms from strong economic systems and targets operating in systems with weaker economies and lower GDP or higher volatility.

Therefore, we expect a positive relationship between economic distance and post M\&A bidder performance by testing the following hypothesis.

\section{Hypothesis 8: Macro-economic distance improves post-performance M\&A for acquiring firms}

By considering bidder investors, private equity funds are becoming a dominant force in M\&A transactions and their influence is growing. Following the literature, there is no wide consensus about the impact of private equity funds as acquirers on target companies in M\&A transactions. However, the main stream of literature on private equity stands that the reduction of costs, strategic focalization, improvement in managerial culture, and opening to other markets have been used to create value in target companies after an M\&A by a private equity fund. According to this literature, we expect an improvement in the post-M\&A performance for target firms.

Hypothesis 9: Private equity funds as acquirers improve post M\&A performance for target firms

\section{Data, Variables and Methodology}

Our empirical tests are based on a sample of cross-border M\&As completed by Italian companies in the period 01/01/2006-31/12/2013. The data on acquisitions were obtained from the MergerMarket database, all financial and accounting variables were obtained from the Bloomberg database and Amadeus database, and the other variables related to culture and macro-economy were extracted from different official websites. The analysis was performed on two different samples, one includes Italian bidder companies and the other includes Italian target companies. 
Table 1. Research criteria for samples selection

\begin{tabular}{lll}
\hline & Italian Bidders sample & Italian Targets sample \\
\hline $\begin{array}{l}\text { Status deal } \\
\text { M\&A completion } \\
\text { date }\end{array}$ & Completed & Completed \\
Type of deal & $01 / 01 / 2006-31 / 12 / 2013$ & $01 / 01 / 2006-31 / 12 / 2013$ \\
$\begin{array}{l}\text { Target } \\
\text { Sector/Industry }\end{array}$ & Cross border M\&A & Cross border M\&A \\
$\begin{array}{l}\text { Bidder } \\
\text { sector/industry } \\
\text { Target countries }\end{array}$ & $\begin{array}{l}\text { all with except for financial services and real estate } \\
\text { North America, Asia, Europe (with except for Italy) }\end{array}$ & $\begin{array}{l}\text { all with except for financial services and real estate } \\
\text { Bidder countries }\end{array}$ \\
$\begin{array}{l}\text { Type of company } \\
\text { Italy }\end{array}$ & Listed and non-listed companies & $\begin{array}{l}\text { North America, Asia, Europe (with except for } \\
\text { industrial as acquirer) }\end{array}$ \\
\hline
\end{tabular}

Based on these criteria, we selected the following database.

Table 2. Research database

\begin{tabular}{lll}
\hline YEARS & Number of Italian Bidder & Number of Italian Target \\
\hline 2006 & 52 & 39 \\
2007 & 78 & 51 \\
2008 & 75 & 61 \\
2009 & 38 & 22 \\
2010 & 45 & 47 \\
2011 & 53 & 57 \\
2012 & 47 & 40 \\
2013 & 27 & 53 \\
Total companies & $\mathbf{4 1 5}$ & $\mathbf{3 7 0}$ \\
\hline
\end{tabular}

Profit and loss statements and balance sheet data were researched for acquirers and targets for 1 year prior to and 3 years after the acquisition. Because most of the companies were private companies, the lack of published data in reports has reduced the total number of deals of the analysis to 415 Italian bidders and 370 Italian targets. For each bidder and target company and with reference to each related acquisition and the two-different analysis performed, in table 3 , we collected the following values according to the main literature.

Table 3. Variables and expected relationship

\begin{tabular}{|c|c|c|c|}
\hline Variable & $\begin{array}{l}\text { Expected performance } \\
\text { post M\&A for bidder }\end{array}$ & $\begin{array}{l}\text { Expected performance } \\
\text { post } M \& A \text { for target }\end{array}$ & Main references \\
\hline \multicolumn{4}{|l|}{ Accounting data } \\
\hline \multicolumn{4}{|l|}{ Growth rate measures } \\
\hline Sales Growth & Improvement & No improvement & (Gugler et al., 2003) \\
\hline Invested capital growth & Improvement & No improvement & \\
\hline Profitability growth & Improvement & No improvement & (Camerlynck et al., 2005) \\
\hline \multicolumn{4}{|c|}{$\begin{array}{l}\text { Profitability and efficiency } \\
\text { indexes }\end{array}$} \\
\hline EBITDA margin & Improvement & No improvement & \\
\hline EBIT margin & Improvement & No improvement & (Gugler et al., 2003)(Abdul Rahman \& Limmack, 2004) \\
\hline Profit Margin & Improvement & No improvement & (Ashfaq et al., 2014) \\
\hline
\end{tabular}




\begin{tabular}{|c|c|c|c|}
\hline ROA & No improvement & No improvement & $\begin{array}{l}\text { Herman \& Lowenstein (1988)(P Mantravadi \& Reddy, } \\
\text { 2008) }\end{array}$ \\
\hline ROIC & No improvement & No improvement & $\begin{array}{l}\text { Herman \& Lowenstein (1988)(P Mantravadi \& Reddy, } \\
\text { 2008) }\end{array}$ \\
\hline Net asset turnover (efficiency) & No improvement & No improvement & \\
\hline \multicolumn{4}{|l|}{ Capital structure measures } \\
\hline LT Debt/Equity & No improvement & No improvement & Rashid e Naeem (2016);(Pilloff, 2006);(Mishra et al., 2012) \\
\hline Net debt/EBITDA & No improvement & No improvement & \\
\hline \multicolumn{4}{|l|}{ Market measures } \\
\hline \multicolumn{4}{|l|}{ Process and actors } \\
\hline Deal value & Improvement & Improvement & \\
\hline $\begin{array}{l}\text { Listing of companies (public } \\
\text { vs private) }\end{array}$ & Improvement & Improvement & (Ragozzino \& Reuer, 2007);(Capron \& Shen, 2007) \\
\hline PE vs Industrial & Improvement & Improvement & \\
\hline \multicolumn{4}{|l|}{ Cultural variables } \\
\hline Hofstede Distance measure & No improvement & No improvement & $\begin{array}{l}\text { (Chakrabarti et al., 2009);(G. Stahl et al., 2013);(Drogendijk } \\
\text { \& Slangen, 2006)(Kogut \& Singh, 2003);(Morosini \& Singh, } \\
\text { 1994)(Dikova \& Rao Sahib, 2013);(Ahammad \& Glaister, } \\
\text { 2013) }\end{array}$ \\
\hline Heritage_Dummy & No improvement & No improvement & \\
\hline \multicolumn{4}{|l|}{ Other market variables } \\
\hline Per capita GDP_diff & Improvement & Improvement & (Collins et al., 2009) (Chakrabarti et al., 2009) \\
\hline $\begin{array}{l}\text { Foreign exchange rate } \\
\text { volatility }\end{array}$ & No improvement & Improvement & (Chakrabarti et al., 2009) \\
\hline Year Dummy & No improvement & No improvement & \\
\hline $\begin{array}{l}\text { Industry growth rate in } \\
\text { revenues }\end{array}$ & Improvement & No improvement & (Pramod Mantravadi \& Reddy, 2008) \\
\hline
\end{tabular}

Generally, companies' features and financial indicators are the main variables in cross-border M\&A performance analysis and they include, for both the bidder and target companies, either profitability and efficiency indices or capital structure measures. Deal characteristics have affected the future success of M\&As. Thus, several deal variables would have been considered in the literature; however, due to the lack of published data, this analysis considers only two deal features: Log_DealValue, which is the logarithm of the deal value in millions of Euros, and PubPri_Dummy, which is a dummy variable with a value 1 if the company is public and 0 if private.

In addition to deal and company features, economic country-level characteristics are likely to influence the success of a cross-border acquisition because, in some cases, the effect of economic and cultural differences between the acquirer and target country on the performance of companies is very relevant as demonstrated in the literature. The variables used in our models have been selected depending on the availability of data and scope of this research. The primary measure is the Hofstede Distance obtained by Geert Hofstede (1980, 2010), taken with the logarithm value (note 4). The Hofstede measure of cultural distance is one of several measures of the degree of dissonance between the socio-legal characteristics of different countries. The second measure is the force of the acquirer country's market-supporting institutions represented by the dummy variable Heritage_Dummy that assumes a value 1 whether the country is free or mostly free (i.e., if the country was classified as one with a "developed institutional environment" or if the mean for the indices used was above 70) and 0 if the country is moderately free or unfree (mean below 70) inside the country rankings of the year in which the acquisition is completed (note 5). The other variables used are as follows: PerCapGDP_diff is a 
measure of the economic disparity between the target firm's nation and acquiring firm's nation (note 6); Forex_Volatility measures the foreign exchange rate volatility between the target nation's currency and acquiring nation's currency-i.e., Euro - as measured by the -36 to -1 month standard deviation, where the month of acquisition is 0 (note 7); Year_Dummy is a dummy variable with value 0 if the acquisition was completed between 2006 and 2009 and 1 if it was completed between 2010 to 2013 (the period chosen reflects the period prior to the financial crisis and the period in which the financial crisis exploded).

To control for industry effects and trend, we used the industry growth in revenues in the last 5 years prior to the acquisition. This rate is the historical growth rate in revenues by industry and by country or US, Europe, and Japan, and emerging markets taken from the Damodaran dataset.

In the analysis of target companies, another variable was considered, the dummy variable indicating the type of bidder: industrial company or private equity funds. Private equity funds include those located in Italy or abroad. The dummy PE_Dummy assumes a value 1 if the Italian company was acquired by a private equity fund or 0 otherwise.

In table 4 , we summarize the variables, labels and positions in two samples.

Table 4. Dataset for multiple regression models

\begin{tabular}{|c|c|c|c|c|}
\hline Variable & Measure & Label & Position & Samples \\
\hline EBITDA margin & Log of (EBITDA/sales) & EBITDA & Dependent & Target \\
\hline EBIT margin & $\log$ of $($ EBIT/Sales $)$ & EBIT & Dependent & Bidder and Target \\
\hline ROIC & $\log$ of ROIC & ROIC & Dependent & Bidder and Target \\
\hline net asset turnover & $\log$ of (sales/asset net non interest liabilities) & TURN & Dependent & Bidder and Target \\
\hline LT Debt/Equity-1 & LT Debt/Equity & LEV & Control & Bidder and Target \\
\hline Net debt/EBITDA & Net debt/EBITDA & $\mathrm{COV}$ & Control & Bidder \\
\hline Hofstede Distance measure & Logaritm of Hofstede Distance & $\mathrm{HF}$ & Explanatory & Bidder and Target \\
\hline Heritage_Dummy & 1 up 70 and 0 down & HD & Explanatory & Bidder \\
\hline Per capita GDP_diff & $\begin{array}{l}\text { (PcapGDP of aquirer nation-PcapGDP of target } \\
\text { nation)/(PcapGDP of acquirer nation+PcapGDP of target } \\
\text { nation) }\end{array}$ & GDP & Explanatory & Bidder \\
\hline Year Dummy & 1 between $2009-2013,0$ before & Y & control & Bidder and Target \\
\hline $\begin{array}{l}\text { Foreign exchange rate } \\
\text { volatility }\end{array}$ & $\begin{array}{l}\text { Forex volatility has been computed for three years prior to } \\
\text { acquisition }\end{array}$ & $\mathrm{EXC}$ & Explanatory & Bidder \\
\hline Deal value & $\log ($ Deal Value $)$ & DV & Explanatory & Bidder and Target \\
\hline Public/private dummy (both) & 1 for listed company, 0 for private company & LIST & Explanatory & Bidder and Target \\
\hline $\begin{array}{l}\text { Industry growth rate in } \\
\text { revenues }\end{array}$ & Historical growth by Damodaran & IGR & Explanatory & Bidder \\
\hline PE Dummy (bidder) & 1 for PE funds, 0 for industrial & $\mathrm{PE}$ & Explanatory & Target \\
\hline
\end{tabular}

We compared the performance of the year before with the three years after the deal using the non-parametric Wilcoxon test that uses the hypothesis on the median of variables examined to determine the differences researched. The null hypothesis of the test is that the two variables are equal in the mean, and the alternative hypothesis (using the test $\mathrm{Z}$ ) is that there are significant differences between the two variables analyzed. It is used to rank data samples by size and eliminates results that are far from the mean average, so called outliers. Next, ordinary least squares (OLS) regression is performed to investigate the determinants of post-M\&A performance for bidder and target companies. In the case of heteroskedasticity, a weighted heteroscedasticity-corrected model was used instead of the OLS model. We then regress post M\&A performance on a list of explanatory variables, including deal-specific, economic and cultural country-level variables.

\subsection{Dependent Variables}

The post M\&A performance for bidder companies is proxied by the natural logarithm of the average EBIT margin (Gugler et al., 2003);(Abdul Rahman \& Limmack, 2004) and the natural logarithm of the average ROIC (Herman \& Lowenstein, 1988). The net asset turnover is used to examine how M\&A influences the efficiency of companies. Specifically, the dependent variables used in the case of acquiring firm samples are as follows: the $\log$ of the EBIT margin post M\&A (mean of three years after deal), log of the ROIC post M\&A (mean of three years after M\&A), and log of the net asset turnover post M\&A (mean of three years after M\&A). The dependent 
variable used in samples with target companies are the log of the EBITDA margin (mean of three years after the deal), the log of the EBIT margin post M\&A (mean of three years after deal) and log of the ROIC post M\&A (mean of three years after the deal). The log of the net asset turnover post M\&A (mean of three years after M\&A).is used to examine how M\&A influences the efficiency of companies.

\subsection{Independent Variables}

Explanatory variables are deal, cultural and macro-economic variables listed previously. Particularly, a change in GDP is used to control for the overall host country's market potential and degree of growth. The exchange rate volatility assesses the average nominal exchange rate differential between the home country (i.e., the United States) and host country in the period, to control for the effects of exchange rate movements on acquisition activity in the subsequent period (Collins et al., 2009). The sample of target companies uses fewer explanatory variables: PubPri_Dummy, cultural variables, and log of the deal value.

Other control variables are the dummy variable related to the year of acquisition and leverage ratio explained by using Debt_Equity and NetDebt_EBITDA of the year prior to the acquisition (the last one is used as control variable only for bidder companies).

To investigate the impact of the type of acquirer (private equity or industrial) on the post M\&A performance of target companies, we performed t-test analysis to identify the differential performance of companies acquired by private equity investors compared with those acquired by industrial partners.

\section{Result of the empirical analysis}

\subsection{Comparison between Pre- and Post-M\&A Performance of Bidder and Target Companies}

The comparison between the operating performance in the year prior to the acquisition and three years later was performed using the non-parametric Wilcoxon test (Tripathi \& Lamba, 2015). This test exploits the hypothesis on the median of the variables. Particularly, the test was performed using test $\mathrm{Z}$ computed for each couple of variables. We compared the year prior to acquisition set as -1 , and the years post acquisition set as $+1,+2,+3$ by using one sample for bidders and another for targets.

The bidder firm results are summarized in table 5 .

Table 5. Hyphothesis test for bidder

\begin{tabular}{|c|c|c|c|}
\hline Data & Test $\mathrm{Z}$ & p-value & Result \\
\hline Profitability growth -1 and +1 & 3.29041 & 0.00100041 & HPl accepted \\
\hline Profitability growth -1 and +2 & 2.54538 & 0.0109158 & HP1 accepted \\
\hline Profitability growth -1 and +3 & -1.25466 & 0.209603 & HP1 rejected \\
\hline Invested capital growth -1 and +1 & 0.903117 & 0.366464 & HP1 rejected \\
\hline Invested capital growth -1 and +2 & 2.02669 & 0.0426945 & HP1 accepted \\
\hline Invested capital growth -1 and +3 & 1.90379 & 0.056937 & HP1 accepted \\
\hline Sales growth -1 and +1 & 0.343541 & 0.731192 & HP1 rejected \\
\hline Sales growth -1 and +2 & 3.89768 & $9.71205 \mathrm{e}-05$ & HPl accepted \\
\hline Sales growth -1 and +3 & 2.70605 & 0.00340444 & HPI accepted \\
\hline EBITDA margin -1 and +1 & 1.63361 & 0.10234 & HP2 rejected \\
\hline EBITDA margin -1 and +2 & 1.4382 & 0.150377 & HP2 rejected \\
\hline EBITDA margin -1 and +3 & 1.36359 & 0.172696 & HP2 rejected \\
\hline EBIT margin- 1 and +1 & 2.3007 & 0.0214089 & HP2accepted \\
\hline EBIT margin- 1 and +2 & 1.96824 & 0.0490408 & HP2 accepted \\
\hline EBIT margin -1 and +3 & -2.68637 & 0.00722332 & $\begin{array}{l}H P 2 \text { rejected. Differently from what } \\
\text { expected, the effect of } M \& A \text { is negative and } \\
\text { significant }\end{array}$ \\
\hline Profit margin -1 and +1 & 2.49417 & 0.0126253 & HP2 accepted \\
\hline
\end{tabular}




\begin{tabular}{llll}
\hline Profit margin -1 and +2 & 3.09234 & 0.00198584 & HP2 accepted \\
Profit margin -1 and +3 & -3.68432 & 0.000229314 & $\begin{array}{l}\text { HP2 rejected. Differently from what expected, } \\
\text { the effect of M\&A is negative and significant }\end{array}$ \\
Return on Assets -1 and +1 & 2.42029 & 0.015508 & HP2 accepted \\
Return on Assets -1 and +2 & -2.13835 & 0.032488 & HP2 rejected \\
Return on Assets -1 and +3 & -2.52204 & 0.0116678 & HP2 rejected \\
Return on Invested Capital -1 and +1 & 2.2313 & 0.0256614 & HP2 accepted \\
Return on Invested Capital -1 and +2 & 2.61119 & 0.00902278 & H2 accepted \\
Return on Invested Capital -1 and +3 & 2.9521 & 0.00315618 & H2 accepted \\
Net asset turnover -1 and +1 & 0.97616 & 0.328985 & HP3 is accepted \\
Net asset turnover -1 and +2 & 0.875974 & 0.381044 & HP3 is accepted \\
Net asset turnover -1 and +3 & 1.14807 & 0.250942 & HP3 is accepted \\
LT Debt/Equity -1 and +1 & -1.545 & 0.122347 & HP4 is accepted \\
LT Debt/Equity -1 and +2 & -1.25486 & 0.209529 & HP4 is accepted \\
LT Debt/Equity -1 and +3 & -0.40550 & 0.685104 & HP4 is accepted \\
\hline
\end{tabular}

This table presents results for bidder by using Wilcoxon test with test $Z$ for variables year prior acquisition and 3 years after. Descriptions of the variables appear in Table 4 . The sample includes Italian companies in the period 01/01/2006-31/12/2013 summarized in Table 2. The data on acquisitions were obtained from the MergerMarket database, all financial and accounting variables were obtained from the Bloomberg database and Amadeus database, and the other variables related to culture and macro-economy were extracted from different official websites. Variables are selected based on main literature mentioned in Table 1.

The results showed that a significant improvement in the net income ( $1 \%$ level of significance) in the two years after the acquisition, while the test $Z-1 ;+3$ was not significant. This seems to suggest a short-term benefit of the acquisition that disappears in 3 years. The change in the invested capital and sales was not significant in the first year after the deal and was significant at the $5 \%$ and $10 \%$ levels in the second and third years after the deal, respectively. Sales showed a significant increase in the second and third years post M\&A. Thus, the first hypothesis is accepted and the results agree with that reported in the literature. The EBIT margin increased significantly in the first and second years after the acquisition, but this benefit seems to disappear in the third year after the deal. The change in the EBITDA margin was not statistically significant. This could be due to the increase in amortization and depreciation due to the increase in invested capital that compensated for the increase in revenues or decrease in other operating costs. Regarding ROA, the positive effect of M\&A was limited to the first year after the transaction. Thus, the M\&A generates a short-term positive effect on the bidders' profitability that disappears within three years after the deal. Return on invested capital (ROIC) showed different results with respect to ROA. More specifically, ROIC increased significantly in all the years after the deal. The net asset turnover was computed as the relationship between the sales and total assets of non-interest bearing liabilities. The change in the capital turnover after the cross-border M\&A transaction was not significant in all the three years. The financial structure had no effect on the M\&A transaction. In fact, the leverage did not show a significant change due to the M\&A transaction. This could be due to different percentages of equity stakes invested in the target company and different sectors involved in the sample.

On the other side target firms results are summarized in table 6. 
Table 6. Hypothesis test for target firms

\begin{tabular}{|c|c|c|c|}
\hline Data & Test $\mathrm{Z}$ & p-value & Result \\
\hline Profitability growth -1 and +1 & 2.15776 & 0.0309468 & HP1 rejected \\
\hline Profitability growth -1 and +2 & 1.7931 & 0.0729577 & HP1 rejected \\
\hline Profitability growth -1 and +3 & 1.41622 & 0.15671 & HP1 accepted \\
\hline Invested capital growth -1 and +1 & 0.681397 & 0.49562 & HP1 accepted \\
\hline Invested capital growth -1 and +2 & 3.01887 & 0.00253724 & HP1 rejected \\
\hline Invested capital growth -1 and +3 & 1.89545 & 0.0580333 & HPI rejected \\
\hline Sales growth -1 and +1 & 0.0155078 & 0.987627 & HP1 accepted \\
\hline Sales growth -1 and +2 & -0.462934 & 0.643412 & HP1 accepted \\
\hline Sales growth -1 and +3 & -0.018536 & 0.985211 & HPl accepted \\
\hline EBITDA margin -1 and +1 & -0.074497 & 0.940615 & HP2 accepted \\
\hline EBITDA margin $\quad-1$ and +2 & 0.748385 & 0.454228 & HP2 accepted \\
\hline EBITDA margin -1 and +3 & -0.310168 & 0.756434 & HP2 accepted \\
\hline EBIT margin -1 and +1 & -0.312083 & 0.754977 & HP2 $b$ accepted \\
\hline EBIT margin -1 and +2 & 0.873193 & 0.382558 & HP2 accepted \\
\hline EBIT margin -1 and +3 & -0.064946 & 0.948217 & HP2 accepted \\
\hline Profit margin -1 and +1 & -0.133791 & 0.893568 & HP2 accepted \\
\hline Profit margin -1 and +2 & 0.765835 & 0.443775 & HP2 accepted \\
\hline Profit margin -1 and +3 & 0.260724 & 0.794305 & HP2 accepted \\
\hline Return on Assets -1 and +1 & 0.728734 & 0.466164 & HP2 accepted \\
\hline Return on Assets -1 and +2 & 1.27981 & 0.200611 & HP2 accepted \\
\hline Return on Assets -1 and +3 & 0.457981 & 0.646966 & HP2 accepted \\
\hline Return on Invested Capital -1 and +1 & 0.0720686 & 0.942547 & HP2 accepted \\
\hline Return on Invested Capital -1 and +2 & 0.681794 & 0.495369 & HP2 accepted \\
\hline Return on Invested Capital -1 and +3 & 0.181121 & 0.856273 & HP2 accepted \\
\hline Net asset turnover -1 and +1 & 2.27775 & 0.0227417 & HP3 is rejected \\
\hline Net asset turnover -1 and +2 & 2.47314 & 0.0133931 & HP3 is rejected \\
\hline Net asset turnover -1 and +3 & 2.97968 & 0.0028855 & HP3 is rejected \\
\hline LT Debt/Equity -1 and +1 & 1.4279 & 0.153322 & HP4 is accepted \\
\hline LT Debt/Equity -1 and +2 & 1.73144 & 0.0833742 & HP4 is rejected \\
\hline LT Debt/Equity -1 and +3 & 2.17928 & 0.0293111 & HP4 is rejected \\
\hline
\end{tabular}

This table presents results for target by using Wilcoxon test with test $\mathrm{Z}$ for variables year prior acquisition and 3 years after. Descriptions of the variables appear in Table 4. The sample includes Italian companies in the period 01/01/2006-31/12/2013 summarized in Table 2. The data on acquisitions were obtained from the MergerMarket database, all financial and accounting variables were obtained from the Bloomberg database and Amadeus database, and the other variables related to culture and macro-economy were extracted from different official websites. Variables are selected based on main literature mentioned in Table 1.

The analysis of target companies showed that the net income increased significantly in the first and second years after the deal, while the changes in sales, in the EBIT/EBITDA margin, ROIC and ROA were not statistically significant.

Target companies do not benefit in terms of profitability in the three years' post M\&A. This trend may be due to a more difficult strategy to catch value from synergies; thus, the time to benefit from a cross-border M\&A on the side of target company could be more than 3 years.

Moreover, if there are no benefits in the profitability, the target companies' efficiency measured by the net asset turnovers increases significantly. Values showed a growing trend of this index from the first to the third year after the deal. This is interesting because it reveals that target companies better manage their assets to generate sales with respect to bidder companies. Because the growing rate in sales is not significantly changing, this result is related to a limited purchase of inventory or less merchandising build up in storage. However, a too-high value of the index could indicate too little investment that might not be good news for a long time.

The last ratio investigated is the leverage in terms of LT debt over equity. As reported above, the first-year post M\&A showed no significant difference in the leverage, and then a significant increase is recorded, especially in the third year. 


\subsection{Type of Acquirer and Effect on the Target Companies' Post-M\&A Performance}

To test hypothesis 9 , we performed several t-tests by dividing the target companies in two subsamples: the first includes target companies acquired by a private equity, and the second includes target companies acquired by an industrial player. For each subsample, we computed the changes in the EBIT margin, ROIC and net asset turnover between the year prior to the acquisition and three years later. The p-value indicates whether the two means are significantly different, while the coefficient of the test shows how they are different.

The results are summarized in the following tables.

Table 7. EBIT margin change in target companies acquired by private equity fund (PE)

\begin{tabular}{lll}
\hline EBIT margin & T-test & p-value \\
\hline$\Delta$ from $-\mathbf{1}$ to $+\mathbf{1}$ & 1.03824 & 0.3004 \\
$\Delta$ from $-\mathbf{1}$ to $+\mathbf{2}$ & 1.60091 & 0.111 \\
$\Delta$ from $-\mathbf{1}$ to $+\mathbf{3}$ & -0.934591 & 0.3512 \\
\hline
\end{tabular}

This table tests the hypothesis that Private equity funds improve targets' post M\&A performance in three years after acquisition (hp 9), by t-tests on EBIT margin dividing the target companies in two subsamples: target companies acquired by PE, and target companies acquired by an industrial player.

In all cases related to changes in the EBIT margin, the p-values were higher than the significance level, indicating that changes in the EBIT margin between the two subsamples does not significantly differ for each year.

Table 8 . ROIC changes in target companies acquired by private equity funds (PEs)

\begin{tabular}{lll}
\hline ROIC & T-test & p-value \\
\hline$\Delta$ from -1 to $+\mathbf{1}$ & -1.01418 & 0.3116 \\
$\Delta$ from -1 to $+\mathbf{2}$ & -0.93921 & 0.3487 \\
$\Delta$ from $-\mathbf{1}$ to $+\mathbf{3}$ & $-0,22146$ & 0.8249 \\
\hline
\end{tabular}

This table tests the hypothesis that Private equity funds improve targets' post M\&A performance in three years after acquisition (hp 9), by t-tests on ROIC dividing the target companies in two subsamples: target companies acquired by $\mathrm{PE}$, and target companies acquired by an industrial player.

Return on invested capital reported the same results and recorded an insignificant difference between the targets acquired by a PE and those acquired by an industrial for each year.

Table 9. Net asset turnover changes in target companies acquired by private equity funds (PEs)

\begin{tabular}{lll}
\hline Net asset turnover & T-test & p-value \\
\hline $\boldsymbol{\Delta}$ from $\mathbf{- 1}$ to $+\mathbf{1}$ & $2.04255^{* * *}$ & 0.04236 \\
$\boldsymbol{\Delta}$ from $\mathbf{- 1}$ to $+\mathbf{2}$ & $2.46886^{* * *}$ & 0.01436 \\
$\boldsymbol{\Delta}$ from $\mathbf{- 1}$ to $+\mathbf{3}$ & 1.54736 & 0.1234 \\
\hline
\end{tabular}

This table tests the hypothesis that Private equity funds improve targets' post M\&A performance in three years after acquisition (hp 9), by t-tests on Net-asset turnover dividing the target companies in two subsamples: target companies acquired by PE, and target companies acquired by an industrial player.

A positive influence by PEs instead is shown in companies' efficiency. Particularly, there is a significant positive difference in the changes from the year prior to acquisition and the two years later between targets acquired by a $\mathrm{PE}$ and others. In the third year, the impact is no longer present. This could be due to the short-term impact of PE.

The findings of the analysis confirmed that, in Italy, private equity investments meet some difficulties that do not guarantee a positive result post M\&A, especially in terms of profitability. This result was also confirmed by some authors in the literature who have observed no significant difference (Wang et al 2003); (Coakley et al 2007);(Meles 2011). 


\subsection{Determinants of Post-M\&A Performance}

Multiple regression analysis was performed using OLS or WLS regression models with Gretl. Two types of test were performed to detect the presence of heteroscedasticity and to determine whether the model is well specified. These tests are the White test and Reset test. The dependent variables selected as measures for M\&A performance are the EBIT margin, EBITDA margin and ROIC as profitability measures and net asset turnover as the efficiency measure. These are models equations to measure bidder performance (Note 1).

$$
\begin{gathered}
\log \left(E B I T_{i}\right)=a+\beta_{L E V}\left(L E V_{i}\right)+\beta_{H F}\left(\log H F_{i}\right)+\beta_{G D P}\left(G D P_{i}\right)+\beta_{E X C}\left(E X C_{i}\right) \\
\log \left(E B I T_{i}\right)=a+\beta_{L E V}\left(L E V_{i}\right)+\beta_{D V}\left(D V_{i}\right)+\beta_{L I S T}\left(L I S T_{i}\right)+\beta_{H D}\left(H D_{i}\right) \\
\log \left(R O I C_{i}\right)=a+\beta_{L E V}\left(L E V_{i}\right)+\beta_{Y}\left(Y_{i}\right)+\beta_{G D P}\left(G D P_{i}\right)+\beta_{I G R}\left(I G R_{i}\right)+\beta_{L I S T}\left(L I S T_{i}\right)+\beta_{H F}\left(\log _{H} F_{i}\right) \\
\log \left(T U R N_{i}\right)=a+\beta_{C O V}\left(C_{C}\right)+\beta_{E X C}\left(E X C_{i}\right)+\beta_{Y}\left(Y_{i}\right)+\beta_{I G R}\left(I G R_{i}\right)
\end{gathered}
$$

The following tables show the main statistics and significance of each multiple regression model for bidder companies.

Table 10. Regression models for bidders

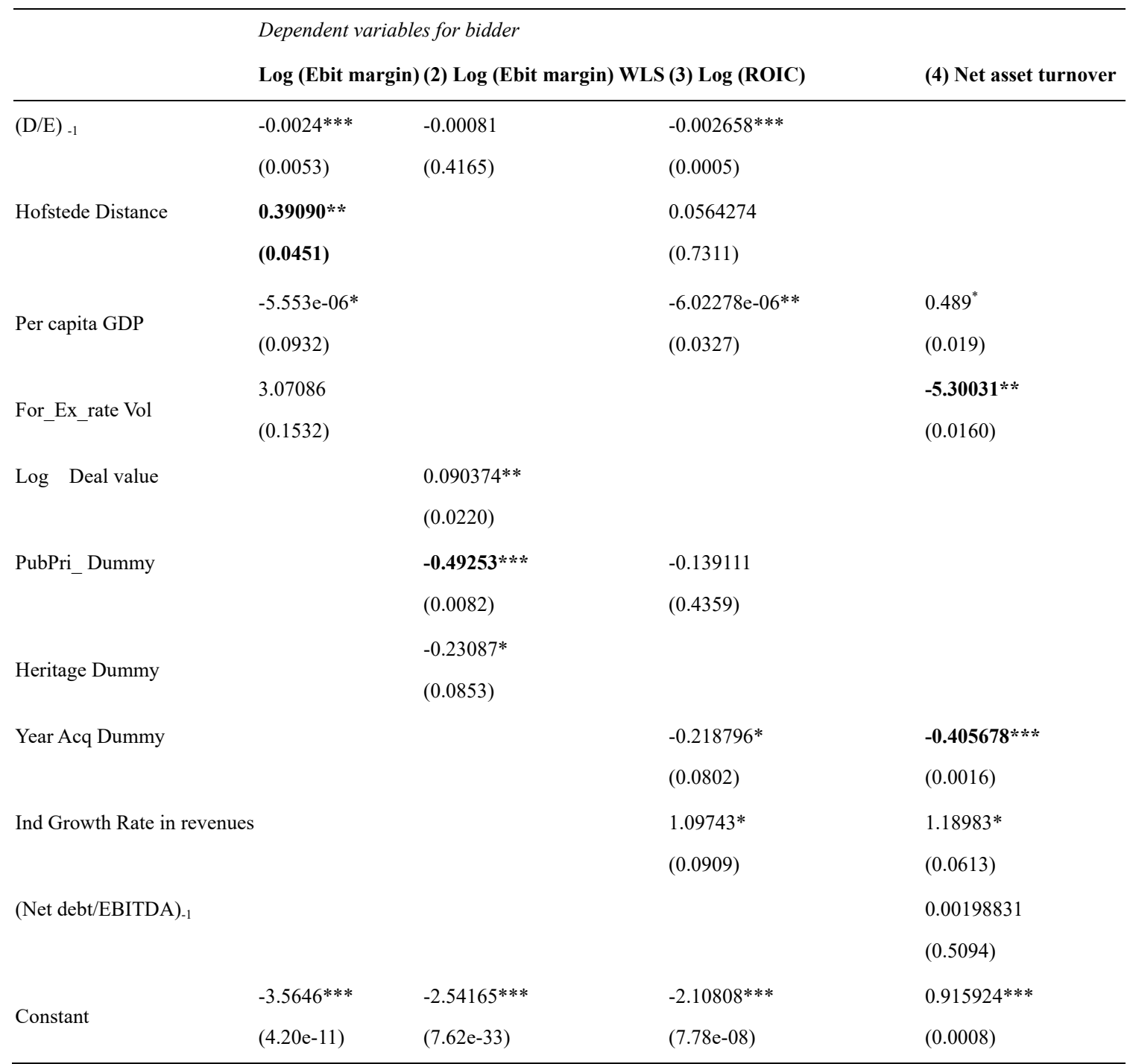

Note. 0 ‘***’0.001 ‘**’0 0.01 '*’0 0.05 ‘’0.1

This table presents results for regression models. Descriptions of the variables appear in Table 4. The first OLS regression model uses the $\log (\mathrm{EBIT})$, margin mean in the three years after the deal as the dependent variable, the second is a WLS regression, while the third uses the $\log (\mathrm{ROIC})$, mean in the three years after the deal as the 
dependent variable and the forth the $\log$ (TURN), net asset turnover .The sample includes Italian companies in the period 01/01/2006-31/12/2013 summarized in Table 2. The data on acquisitions were obtained from the MergerMarket database, all financial and accounting variables were obtained from the Bloomberg database and Amadeus database, and the other variables related to culture and macro-economy were extracted from different official websites. ., ${ }^{* * *}$, and ${ }^{* * *}$ indicate significance level at the $0.10,0.05,0.01$ and 0.001 respectively.

The first OLS regression model used the log of the EBIT margin mean in the three years after the deal as the dependent variable, the debt over equity as the control variable and the Hofstede distance, per capita GDP difference and foreign exchange rate volatility as explanatory variables. The first model was confirmed using the Reset test and White test. All the variables were significant with the exception of foreign exchange rate volatility. Cultural variables have a positive coefficient, which is very interesting because it leads to the rejection of hypothesis 7. Some subscribers to the resource-based view confirmed this result in their studies. Even if the cultural distance showed by the Hofstede distance revealed a good interaction, the per capita GDP difference reported a negative coefficient. Thus, if the difference in terms of the GDP between the target and bidder country grows, a negative impact on the EBIT margin is recorded. Model (2) suggests that the size of the deal has a positive effect on the post M\&A operating margin, probably due to greater economies of scale. Thus, hypothesis 6 is accepted. The dummy variable "PubPri" exerts negative and significant effects on the operating margins: when the target and bidder are listed companies, the operating margin is negatively affected (Capron \& Shen, 2007). Thus, hypothesis 5 is rejected. However, as already explained, the literature about the impact of this variable is not homogeneous. Heritage_Dummy displays a negative coefficient, indicating that, if target companies are located in countries with higher economic freedom, the M\&A post-operating performance in bidder companies is lower.

To consider an adjusted value creation driver, we also studied the determinants of post M\&A ROIC. Knowing that the year of acquisition is a dummy variable assuming value 1 in the case of acquisition in the period of crisis, the result showed that the post M\&A performance is worse if the deal is completed during the financial crisis. As reported in several analyses on Italian companies (Kpmg, 2018), those that realized M\&A operations seem to be more prudent. This prudence is often translated into a preference of the target companies to operate in the same sector or to be located in the same market. Thus, a financial crisis obviously plays a role in decisions about M\&A strategy. However, the impact of a financial crisis is not so trivial. In fact, in a period of crisis, a reduction in the value and number of M\&A operations is expected but a higher number of transactions to catch opportunities could be recorded (e.g., acquisitions of companies in a difficult situation). The cultural distance and industry growth rate in revenues exert a positive and significant effect on bidder ROIC, while the per-capita GDP and PubPri_Dummy generate a negative impact.

With the aim to study also the effect on efficiency, the final variable analyzed is the Net asset turnover. The model is the WLS model that was built due to stationarity among variables. Foreign exchange rate volatility has a negative coefficient with a $5 \%$ level of significance, indicating that the volatility between the currencies of the two countries involved in the M\&A reduces the bidder efficiency. The results concerning the year of acquisition and industry growth rate are the same as those in profitability analysis. Additionally, in this model, the impact of the cultural variable was not considered because of its lack of significance, except for the per-capita GDP that generates a positive impact contrary to previous models. Moreover, as expected, companies belonging to growing industries show a higher efficiency after an M\&A deal.

For target companies, we select only these significant variables and apply these four models with the following results:

$$
\begin{aligned}
& \log \left(E B I T D A_{i}\right)=a+\beta_{P E}\left(P E_{i}\right)+\beta_{H D}\left(H D_{i}\right)+\beta_{H F}\left(H F_{i}\right)+\beta_{L I S T}\left(L I S T_{i}\right)+\beta_{Y}\left(Y_{i}\right)+\beta_{D V}\left(D V_{i}\right) \\
& \log \left(E B I T_{i}\right)=a+\beta_{H F}\left(\log H F_{i}\right)+\beta_{D V}\left(D V_{i}\right)+\beta_{Y}\left(Y_{i}\right)+\beta_{L E V}\left(L E V_{i}\right) \\
& \log \left(R O I C_{i}\right)=a+\beta_{H F}\left(\log H F_{i}\right)+\beta_{D V}\left(D V_{i}\right)+\beta_{Y}\left(Y_{i}\right)+\beta_{L E V}\left(L E V_{i}\right) \\
& \log \left(T U R N_{i}\right)=a+\beta_{H F}\left(H F_{i}\right)+\beta_{D V}\left(D V_{i}\right)+\beta_{L I S T}\left(L I S T_{i}\right)++\beta_{Y}\left(Y_{i}\right)+\beta_{L E V}\left(L E V_{i}\right)
\end{aligned}
$$

Table 11. Regression models for targets

Dependent variables for target 


\begin{tabular}{|c|c|c|c|c|}
\hline & (1) Log (Ebitda margin) & (2) Log (Ebit margin) & (3) $\log ($ ROIC) & (4) Net asset turnover \\
\hline PE Dummy & $\begin{array}{l}0.212560 \\
(0.3250)\end{array}$ & & & \\
\hline Hofstede Distance & $\begin{array}{l}-0.242173 * * \\
(0.0181)\end{array}$ & & & $\begin{array}{l}0.335941^{*} \\
(0.0799)\end{array}$ \\
\hline Heritage Dummy & $\begin{array}{l}0.321234^{*} \\
(0.0963)\end{array}$ & $\begin{array}{l}0.507214 * \\
(0.0608)\end{array}$ & $\begin{array}{l}-0.168531 \\
(0.4800)\end{array}$ & \\
\hline Log Deal value & $\begin{array}{l}0.095879 * \\
(0.0571)\end{array}$ & $\begin{array}{l}\mathbf{0 . 2 3 2 3 1 6 * * *} \\
(0.0005)\end{array}$ & $\begin{array}{l}-0.225199 \\
(2.602)\end{array}$ & $\begin{array}{l}-0.128581 \\
(0.1162)\end{array}$ \\
\hline PubPri_Dummy & $\begin{array}{l}-0.481641 \\
(0.1729)\end{array}$ & & & $\begin{array}{l}0.925293 * \\
(0.0784)\end{array}$ \\
\hline Year Acq Dummy & $\begin{array}{l}\mathbf{0 . 3 1 7 9 5 6 * *} \\
(0.0476)\end{array}$ & $\begin{array}{l}\mathbf{0 . 6 3 6 8 3 6 * *} \\
(0.0473)\end{array}$ & $\begin{array}{l}-\mathbf{0 . 8 9 3 0 1 7 * *} \\
(0.0402)\end{array}$ & $\begin{array}{l}0.204287 \\
(0.5875)\end{array}$ \\
\hline$(\mathrm{D} / \mathrm{E})_{-1}$ & & $\begin{array}{l}-0.0106367 \\
(0.5892)\end{array}$ & $\begin{array}{l}-0.0735639 * * * \\
(0.0069)\end{array}$ & $\begin{array}{l}-0.00581258 \\
(0.7901)\end{array}$ \\
\hline Constant & $\begin{array}{l}1.98219 * * * \\
(3.01 \mathrm{e}-13)\end{array}$ & & & \\
\hline
\end{tabular}

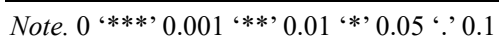

This table presents results for regression models. Descriptions of the variables appear in Table 4. The first OLS regression model uses the log (EBITDA) margin mean in the three years after the deal as the dependent variable, the second the $\log (\mathrm{EBIT})$ margin mean, while the third uses the $\log (\mathrm{ROIC})$, mean in the three years after the deal as the dependent variable and the forth the $\log$ (TURN), net asset turnover. The sample includes Italian companies in the period 01/01/2006-31/12/2013 summarized in Table 2. The data on acquisitions were obtained from the MergerMarket database, all financial and accounting variables were obtained from the Bloomberg database and Amadeus database, and the other variables related to culture and macro-economy were extracted from different official websites. ${ }^{*},{ }^{* *}$, and $* * *$ indicate significance level at the $0.10,0.05,0.01$ and 0.001 , respectively.

As displayed in table 11, in the case of target companies, the log of the post M\&A EBITDA margin was negatively affected by cultural differences and positively affected by the deal value and year of acquisition. In contrast to the bidder companies' results, Heritage_Dummy has a positive coefficient with a $10 \%$ level of significance, indicating that, if the bidder country is economically free, there is a positive influence on Italian target companies. The negative coefficient of the Hofstede distance revealed that the larger is the cultural distance between the target and bidder country, the lower is the post M\&A EBITDA margin. Thus, hypothesis 7 is rejected, moreover there is a different relationship from that of the bidder, except in model 4 with a positive coefficient linked to the net asset turnover growth. Regarding the year of acquisition, a financial crisis could be a way to reach opportunities for target companies. In fact, the results demonstrate, different from bidder companies that, from 2010 to 2013, the post M\&A performance for Italian target companies improved. The result of the log of the deal value was the same as that for bidder companies. PubPri_Dummy and PE_Dummy were not significant except for the net asset turnover.

\section{Conclusions}

This paper analyzed the cross-border M\&A post performance in 415 Italian bidder companies with acquisitions completed in Asia, North America and Europe and 370 Italian target companies acquired by companies located in Asia, North America and Europe. We considered the period post M\&A with a time range from 2006 to 2013 by analyzing three years before M\&A and three years post. All the included companies belonged to the non-financial sectors. Post-performance was measured using financial variables such as growth, profitability, efficiency and financial structure up to three years' post M\&A (the year of acquisition was not considered). Moreover, the impact of external factors such as deal features, economic trends, uncertainty, country risk and culture was computed. A specific analysis of the change in performance between the year prior to M\&A and the three years later based on the type of acquirer - that is, Private equity fund or Industrial - has been evaluated. This research attempted to evaluate synergies from cross-border M\&A deals measuring value creation and the impact of external market factors. 
The final outcome can be summarized in table 12 .

Table 12. Result of the overall analysis on bidder and target performance

\begin{tabular}{|c|c|c|c|c|}
\hline Dependent variables & $\begin{array}{l}\text { Expected effect for bidder } \\
\text { based on literature }\end{array}$ & Results & $\begin{array}{l}\text { Expected effect for target } \\
\text { based on literature }\end{array}$ & Results \\
\hline Sales Growth & + & + & Non sign. & Non sign. \\
\hline Profit growth & + & + & Non sign. & + (first 2 years). \\
\hline Invested capital growth & + & + & Non sign. & + (last 2 years) \\
\hline EBITDA margin & + & + & Non sign. & Non sign. \\
\hline EBIT margin & + & $+($ no year 3$)$ & Non sign. & - \\
\hline Profit margin & + & + & Non sign. & Non sign. \\
\hline ROA & Non sign. & - & Non sign. & Non sign. \\
\hline ROIC & Non sign. & + & Non sign. & Non sign. \\
\hline Capital Turnover & Non sign. & Non sign. & Non sign. & + \\
\hline Leverage & Non sign. & Non sign. & Non sign. & + (last 2 years) \\
\hline Independent variables and control & $\begin{array}{l}\text { Expected effect on bidder } \\
\text { performance }\end{array}$ & Results & $\begin{array}{l}\text { Expected effect on target } \\
\text { performance }\end{array}$ & Results \\
\hline Leverage & - & - & - & - \\
\hline $\begin{array}{l}\text { Cultural distance in socio-legal } \\
\text { characteristics (Hofstede Distance) }\end{array}$ & Non sign. & + & Non sign. & - \\
\hline $\begin{array}{l}\text { Cultural distance in development } \\
\text { (Heritage Distance) }\end{array}$ & Non sign. & - & Non sign. & + \\
\hline Macroeconomic distance in GDP & + & - & Non sign. & Non sign. \\
\hline Year Dummy (Deal in years of crisis) & - & - & - & + \\
\hline Forex volatility & - & - & - & Not disposable \\
\hline Deal value & + & + & + & + \\
\hline Listing & + & - & + &.+ \\
\hline Industry growth rate & + & + & + & Not disposable \\
\hline PE presence & + & Not disposable & + & - (with T test) \\
\hline
\end{tabular}

This table reports final results of analysis and highlight that EBITDA, EBIT and profit margins, ROA and ROIC display an increase in bidder companies, while target companies do not reveal any significant difference between the period pre-M\&A and post period, and there is a significant EBIT margin reduction. The cultural distance in terms of socio-legal characteristics exerts a positive effect on post M\&A bidder companies' performance and negative in target companies.

Generally, we noted a better impact on bidder companies caused by an M\&A transaction with respect to target firms. Growth in terms of profitability and invested capital has been recorded in both samples, while sales have grown only in bidder companies. Profitability ratios (EBITDA, EBIT and profit margins, ROA and ROIC) display an increase in short term in bidder companies, while target companies do not reveal any significant difference between the period pre-M\&A and post period, and there is a significant EBIT margin reduction. Thus, in bidder companies, there was optimization in terms of the operating costs that did not appear in target companies. Efficiency, measured by the net asset turnover, showed an interesting result. In fact, in terms of efficiency target companies perform better than bidder ones after an M\&A transaction. The financial leverage in bidder companies does not change significantly after M\&A transaction, while target companies have higher leverage after a cross-border M\&A. Cultural, economic and deal factors showed partially unexpected results (not the same variables were considered in both samples) if we consider their impact on bidder and target performance. Particularly, the cultural distance in terms of socio-legal characteristics exerts a positive effect on post M\&A bidder companies' performance and negative in target companies. This finding indicates that bidder companies better exploit source of value in terms of competencies and resources, learning from their counterparties. Thus, internationalization in terms of acquiring strategic assets in various markets can make bidders more competitive. On the other hand, targets encounter problems inside the integration process. Additionally, for what concerns the country risk, differently from previous studies, the per capita GDP difference and cultural distance (Heritage index) have a negative impact on bidder companies. These findings demonstrate that the economic growth distance plays a relevant role in explaining performance in an M\&A transaction, while 
cultural distance in socio-legal characteristics exerts a significant positive influence. Forex volatility has the expected negative impact on bidder performance and the industry growth according to the main literature exerts a positive influence. Economic and financial uncertainty, shown in Year Dummy, implies a negative impact on bidder performance, but in these periods Italian targets' performance increases with difference to ASEAN countries (Rao-Nicholson et al., 2016). Moreover deal value positively influences the performance of bidder and target companies: even if small acquisitions may be easier to execute and integrate, they do not move the increase in revenues, do not generate many synergies and do not leverage the acquirer's full financial and organizational capacity. We also demonstrate that transactions among private companies record better results in terms of post M\&A performance, especially for bidder companies. This means that even if a lack of information increases the risk of not evaluating targets properly, companies are attracted by interesting growth opportunities they can provide in the future. In private company transactions, contractual confidentiality obligations provide the deal participants with flexibility in negotiations. Instead, public deal terms are much more market driven with less variation among deals. The decision related to complete an M\&A among private companies is often the consequence of the slowdown in revenues: a private $M \& A$ is seen as a way to not lose competitive power. Finally, our analysis shed light on the role of private equity funds as acquirers in a cross-border M\&A, demonstrating that target companies acquired by private equity funds do not benefit in terms of profitability from the acquisition.

Generally we can assess that cross-border M\&As help companies to be more competitive and under political and financial uncertainty they exert a positive effect on bidders and targets performance after the operation. This phenomenon can be due either to economy of scale and synergies either to diversification benefits.

Our analysis is affected by several limitations. The first is related to the localization of bidder and target companies in Italy. The use of a European sample may allow achievement of the most relevant results and the generalization our findings. With larger samples, an analysis by industrial sector would detect the different impacts of cross-border M\&A in each industry. Moreover, different financial measures can be used to examine performance post M\&As. Finally, stock market reaction has not been considered in this research.

\section{References}

Abdul Rahman, R., \& Limmack, R. J. (2004). Corporate acquisitions and the operating performance of Malaysian companies. Journal of Business Finance and Accounting. https://doi.org/10.1111/j.0306-686X.2004.00543.x

Ahammad, M. F., \& Glaister, K. W. (2013). The pre-acquisition evaluation of target firms and cross border acquisition performance. International Business Review. https://doi.org/10.1016/j.ibusrev.2013.01.001

Alexandridis, G., Mavrovitis, C. F., \& Travlos, N. G. (2012). How have M\&As changed? Evidence from the sixth merger wave. European Journal of Finance. https://doi.org/10.1080/1351847X.2011.628401

Anand, J., Capron, L., \& Mitchell, W. (2005). Using acquisitions to access multinational diversity: Thinking beyond the domestic versus cross-border M\&A comparison. Industrial and Corporate Change. https://doi.org/10.1093/icc/dth044

Antikainen, K. (2008). Evaluation of Success of Mergers and Acquisitions - Case Finnish Forest Companies. SSRN. https://doi.org/10.2139/ssrn.498247

Ashfaq, K., Usman, M., Hanif, Z., \& Yousaf, T. (2014). Investigating the Impact of Merger \& Acquisition on Post Merger Financial Performance (Relative \& Absolute) of Companies (Evidence from Non-Financial Sector of Pakistan). International Journal of Academic Research in Business and Social Sciences. https://doi.org/10.6007/ijarbss/v4-i11/1307

Aybar, B., \& Ficici, A. (2009). Cross-border acquisitions and firm value: An analysis of emerging-market multinationals. Journal of International Business Studies. https://doi.org/10.1057/jibs.2009.15

Bertrand, O., \& Betschinger, M. A. (2012). Performance of domestic and cross-border acquisitions: Empirical evidence from Russian acquirers. Journal of Comparative Economics. https://doi.org/10.1016/j.jce.2011.11.003

Camerlynck, J., Ooghe, H., \& De Langhe, T. (2005). Pre-acquisition profile of privately held companies involved in take-overs: An empirical study. Small Business Economics. https://doi.org/10.1007/s11187-003-3807-2

Capron, L., \& Shen, J. C. (2007). Acquisitions of private vs. public firms: Private information, target selection, and acquirer returns. Strategic Management Journal. https://doi.org/10.1002/smj.612 
Cartwright, S., \& Cooper, C. L. (2011). The role of culture compatibility in successful organizational marriage. Academy of Management Perspectives. https://doi.org/10.5465/ame.1993.9411302324

Chakrabarti, R., Gupta-Mukherjee, S., \& Jayaraman, N. (2009). Mars-Venus marriages: Culture and cross-border M \& A. Journal of International Business Studies. https://doi.org/10.1057/jibs.2008.58

Clark, K., \& Ofek, E. (2006). Mergers as a Means of Restructuring Distressed Firms: An Empirical Investigation. The Journal of Financial and Quantitative Analysis. https://doi.org/10.2307/2331109

Collins, J. D., Holcomb, T. R., Certo, S. T., Hitt, M. A., \& Lester, R. H. (2009). Learning by doing: Cross-border mergers and acquisitions. Journal of Business Research. https://doi.org/10.1016/j.jbusres.2008.11.005

Dikova, D., \& Rao Sahib, P. (2013). Is cultural distance a bane or a boon for cross-border acquisition performance? Journal of World Business. https://doi.org/10.1016/j.jwb.2012.06.009

Drogendijk, R., \& Slangen, A. (2006). Hofstede, Schwartz, or managerial perceptions? The effects of different cultural distance measures on establishment mode choices by multinational enterprises. International Business Review. https://doi.org/10.1016/j.ibusrev.2006.05.003

Ghosh, A. (2001). Does operating performance really improve following corporate acquisitions? Journal of Corporate Finance. https://doi.org/10.1016/S0929-1199(01)00018-9

Gugler, K., Mueller, D. C., Yurtoglu, B. B., \& Zulehner, C. (2003). The effects of mergers: An international comparison. International Journal of Industrial Organization. https://doi.org/10.1016/S0167-7187(02)00107-8

Kiymaz, H. (2013). Cross-border mergers and acquisitions and country risk ratings: evidence from u.s. financials. International Journal of Business and Finance.

Kogut, B., \& Singh, H. (2003). The Effect of National Culture on the Choice of Entry Mode. Journal of International Business Studies. https://doi.org/10.1057/palgrave.jibs.8490394

Kumar, S., \& Bansal, L. K. (2008). The impact of mergers and acquisitions on corporate performance in India. Management Decision. https://doi.org/10.1108/00251740810920029

Linn, S. C., \& Switzer, J. A. (2001). Are cash acquisitions associated with better postcombination operating performance than stock acquisitions? Journal of Banking and Finance. https://doi.org/10.1016/S0378-4266(00)00108-4

Mantravadi, P., \& Reddy, A. (2008). Type of merger and impact on operating performance: the indian experience. Economic and Political Weekly.

Mantravadi, Pramod, \& Reddy, V. (2008). PostMerger Performance of Acquring Firms from Different Industries in India. International Research Journal of Finance And Economic. https://doi.org/10.1080/00365540600617009

Megginson, W. L., Morgan, A., \& Nail, L. (2004). The determinants of positive long-term performance in strategic mergers: Corporate focus and cash. Journal of Banking and Finance. https://doi.org/10.1016/S0378-4266(02)00412-0

Mergermarket. (2017). Cross-border M\&A index. Global Issues. https://doi.org/10.1016/j.ijindorg.2005.07.006

Mishra, C. S., Leepsa, N. M., Sekhar, C., Corresponding, M., \& Gupta, V. (2012). Post Merger Financial Performance: A Study with Reference to Select Manufacturing Companies in India. International Research Journal of Finance and Economics.

Moeller, S. B., Schlingemann, F. P., \& Stulz, R. M. (2004). Firm size and the gains from acquisitions. Journal of Financial Economics. https://doi.org/10.1016/j.jfineco.2003.07.002

Morosini, P., \& Singh, H. (1994). Post-cross-border acquisitions: Implementing "national culture-compatible" strategies to improve performance. European Management Journal. https://doi.org/10.1016/0263-2373(94)90025-6

Nadolska, A., \& Barkema, H. G. (2007). Learning to internationalise: The pace and success of foreign acquisitions. Journal of International Business Studies. https://doi.org/10.1057/palgrave.jibs. 8400318

Neary, J. P. (2007). Cross-border mergers as instruments of comparative advantage. Review of Economic Studies. https://doi.org/10.1111/j.1467-937X.2007.00466.x

Pilloff, S. J. (2006). Performance Changes and Shareholder Wealth Creation Associated with Mergers of Publicly 
Traded Banking Institutions. Journal of Money, Credit and Banking. https://doi.org/10.2307/2077976

Ragozzino, R., \& Reuer, J. J. (2007). Mind the Information Gap: Putting New Selection Criteria and Deal Structures to Work in M\&A. Journal of Applied Corporate Finance. https://doi.org/10.1111/j.1745-6622.2007.00149.x

Rao-Nicholson, R., Salaber, J., \& Cao, T. H. (2016). Long-term performance of mergers and acquisitions in ASEAN countries. Research in International Business and Finance. https://doi.org/10.1016/j.ribaf.2015.09.024

Rashid, A., \& Naeem, N. (2017). Effects of mergers on corporate performance: An empirical evaluation using OLS and the empirical Bayesian methods. Borsa Istanbul Review. https://doi.org/10.1016/j.bir.2016.09.004

Sarala, R. M., Junni, P., Cooper, C. L., \& Tarba, S. Y. (2016). A Sociocultural Perspective on Knowledge Transfer in Mergers and Acquisitions. Journal of Management. https://doi.org/10.1177/0149206314530167

Stahl, G., Björkman, I., Goulet, P. K., \& Schweiger, D. M. (2013). Managing Culture and Human Resources in Mergers and Acquisitions. In Handbook of Research in International Human Resource Management. https://doi.org/10.4337/9781845428235.00029

Stahl, G. K., \& Voigt, A. (2007). Do Cultural Differences Matter in Mergers and Acquisitions? A Tentative Model and Examination. Organization Science. https://doi.org/10.1287/orsc.1070.0270

Tetenbaum, T. J. T. (1999). Beating the Odds of Merger \& Acquisition Failure: Seven Key Practices That Improve the Chance for Expected Integration and Synergies. Organizational Dynamics.

Tripathi, V., \& Lamba, A. (2015). What drives cross-border mergers and acquisitions?: A study of Indian multinational enterprises. Journal of Strategy and Management. https://doi.org/10.1108/JSMA-05-2015-0040

Yeh, T., \& Hoshino, Y. (2002). Productivity and operating performance of Japanese merging firms: Keiretsu-related and independent mergers. Japan and the World Economy. https://doi.org/10.1016/S0922-1425(01)00081-0

\section{Notes}

Note 1. This approach examines abnormal stock returns to the shareholders of both bidders and target around the announcement of an offer and includes both successful (i.e., completed transactions) and unsuccessful M\&A, it is called event studies and the event is the M\&A announcement.

Note 2. Several studies are based on multiple performance measures that may not be classified purely due to accounting measures or event studies.

Note 3. Cross M\&As enable acquirers to access foreign markets more quickly than in other modes of entry, and they are sometimes less risky than Greenfield investments.

Note 4. Hofstede's index is the combination of different cultural values that have been used to quantify and compare from different perspectives, either cultural proximity or distance among countries. The Hofstede index measures the cross-cultural distance among countries from six numerical dimensions: power distance, individualism, masculinity, avoidance, long-term orientation and indulgence. The measure is

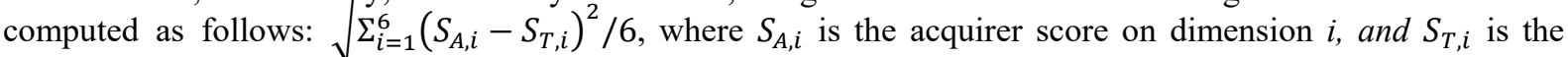
target score on dimension $I$ ( $i$ dimensions are those listed above). Source: Hofstede-insights.com website, Mars-Venus marriages: Culture and cross-border $M \& A$ (Rajesh Chakrabarti, Swasti Gupta-Mukherjee, Narayanan Jayaraman, 2007).

Note 5. From Heritage Foundation's Economic Freedom Index website, this represents the indices that best reflect the efficiency of a market: business freedom, trade freedom, investment freedom, financial freedom, and property rights. For each country and year in the sample, the mean of values obtained for the five economic freedom indices in the acquirer's country is computed. Source: Adriana Bruscato Bortoluzzo, Maria Pia de Siqueira Garcia, Dirk Michael Boehe, Hsia Hua Sheng, Performance in cross-border mergers and acquisitions: an empirical analysis of the Brazilian case, 2014.

Note 6. This measure is computed as PCI_Diff $=($ Per capita GDP of acquirer nation-Per capita GDP of target nation)/(Per capita GDP of acquirer nation+Per capita GDP of target nation). Source: Rajesh Chakrabarti, Swasti Gupta-Mukherjee, Narayanan Jayaraman, Mars-Venus marriages: Culture and cross-border M\&, 2007. Data are collected from worldbank website. 
Note 7. After having collected journal foreign exchange rates from the Bank of Italy dataset for each currency of each target country, volatility was computed for three years prior to acquisition.

Note 8 . The number of observations used in each model is lower than that of deals included in our study due to the missing values. More specifically, we have the following information: 205 observations for the model 1 bidder, 163 observations for the model 2 bidder, 184 observations for the model 3 bidder, 215 observations for the model 4 bidder, 188 observations for the Model 1 Target, 289 observations for the model 1 and 3 targets; 183 observations for the model 5 target.

\section{Copyrights}

Copyright for this article is retained by the author(s), with first publication rights granted to the journal.

This is an open-access article distributed under the terms and conditions of the Creative Commons Attribution license (http://creativecommons.org/licenses/by/4.0/). 